\title{
ABS/recycled PCTG blend compatibilized with ionomer: effect on impact resistance and morphology
}

\author{
Juliana Augusto Molari ${ }^{1 *}$ (D) and Deborah Dibbern Brunelli ${ }^{1}$ (D) \\ ${ }^{1}$ Instituto Tecnológico de Aeronáutica - ITA, São José dos Campos, SP, Brasil \\ *juliana_augusto89@yahoo.com.br
}

\begin{abstract}
The effect of adding ionomer as a compatibilizing agent in ABS/recycled PCTG blend was the objective of this study. Design of experiments using extreme vertices was used, to obtain a mathematical equation to predict the result of the impact resistance of blends, within a pre-established interval. The sample that obtained the highest impact resistance was the 79/20/1 (ABS/PCTG/Ionomer) and was analyzed by DSC and SEM. The results showed partial compatibility. Through the analysis of the fracture surface of the Charpy test specimen, it was verified that the PCTG, as a dispersed phase, presented itself in the form of fibers and the ionomer acted as an emulsifier. All results showed that it is possible to reuse PCTG industrial waste by mixing it with ABS and Ionomer as compatibilizing agent.
\end{abstract}

Keywords: $A B S, P C T G$, ionomer, polymeric blend, compatibilization.

How to cite: Molari, J. A., \& Brunelli, D. D. (2021). ABS/recycled PCTG blend compatibilized with ionomer: effect on impact resistance and morphology. Polimeros: Ciência e Tecnologia, 31(3), e2021028. https://doi.org/10.1590/01041428.20210070

\section{Introduction}

Plastic waste has become a worldwide environmental problem once it has been accumulated on the ecosystems across the globe ${ }^{[1,2]}$. Several plastics waste streams come from packaging, construction, and automotive industry ${ }^{[1,2]}$. In order to reduce the environmental impact of plastics, different technologies for plastic mechanical recycling have been developed ${ }^{[3]}$.

The main method of enhancing the properties of the plastic waste materials consists of adding new components in the mixture: virgin polymer content, compatibilizers and stabilizers ${ }^{[3-5]}$.

The acrylonitrile-butadiene-styrene (ABS) polymer is a terpolymer widely used in the automotive and home appliance industries. The properties of the ABS polymer vary according to the proportion of its monomers ${ }^{[6]}$.

The PCTG copolyester is a copolymer formed by the esterification and polycondensation reaction of cyclohexanedimethanol (CHDM), terephthalic acid (TPA) and ethylene glycol (EG). If the CHDM content in the copolyester is less than $50 \%$, the copolymer is called PETG, and when it is greater than $50 \%$, it becomes the PCTG. PCTG is widely used in the packaging industry and is very susceptible to hydrolytic thermal oxidation, which can cause discoloration/yellowing and chain scission. For this reason, the mechanical recycling of this material is not widely recommended, which makes it very difficult to reuse PCTG after its life cycle ${ }^{[7-9]}$.

ABS and PCTG polymers have different polarities and are not fully compatible, therefore obtaining a blend between them requires the use of compatibilizing agents ${ }^{[10]}$.

Ionomers are polymers that have ionic groups in their molecular structure resulting from the neutralization of sulfonic acid or carboxylic acid groups and can be used as compatibilizing agents in polymer blends ${ }^{[11]}$.

This work aims the study of the effectiveness of the ionomer matching agent Surlyn ${ }^{\circledR}$ in the blend between $\mathrm{ABS}$ and PCTG, in order to develop a method of reusing industrial waste from PCTG. Strategic planning and execution of experiments (Design of Experiments - DOE) were used to search for the optimum conditions for this multivariable system.

For the modeling of mixtures, the data can be adjusted by simplex-lattice, simplex-centroid or extreme vertices. Modeling by extreme vertices is the most appropriate method, using pseudocomponent, if there are upper and lower limit constraints on components.

\section{Experimental}

\subsection{Materials}

Materials used in this work included ABS polymer Terluran ${ }^{\circledR}$ GP22, supplied by Styrolution ${ }^{\mathrm{TM}}$, PCTG SKYGREEN ${ }^{\circledR}$ JN400 industrial waste from SK Chemicals ${ }^{\mathrm{TM}}$ (obtained from leftover scrap resulting from injection molded parts from packaging industry) and the ionomer Surlyn ${ }^{\circledR}$ PC 2000, supplied by DuPont ${ }^{\mathrm{TM}}$.

\subsection{Experimental design and blend preparation}

MINITAB ${ }^{\circledR}$ software was used to elaborate the modeling of the experiments by pseudocomponents and extreme 
vertices of third degree. The software was also used to complete the analysis of the data by analysis of variance (ANOVA) for the mixture of the components: ABS (X1), PCTG (X2) and ionomer (X3).

Pseudocomponent modeling and extreme vertices were used for compatibilized blends, with mass percentage ranges of $30 \% \leq \mathrm{ABS} \leq 80 \%, 20 \% \leq \mathrm{PCTG} \leq 60 \%$ and $1 \% \leq$ Ionomer $\leq 7 \%$. The MINITAB $\AA$ software generated 13 runs for each formulation where the Charpy impact resistance was determined experimentally for each run prior to model. Each central point of the experiment was repeated at least three times. The total ratio for each formulation adds up to a total of $100 \%$ for a mass of $100 \mathrm{~g}$, as presented in Table 1 .

Samples were first weighed, cold mixed, and then extruded using a twin screw extruder in order to ensure an adequate homogeneity. Prior to the injection molding of the test specimens, all extruded mixtures were dried in a dehumidifying dryer at $80{ }^{\circ} \mathrm{C}$ for 4 hours.

\subsection{Differential scanning calorimetry measurements (DSC)}

The DSC experiments were conducted using Mettler's model 822e. Measurements were performed using the second heating from $-120{ }^{\circ} \mathrm{C}$ to $250{ }^{\circ} \mathrm{C}$ at a ratio of $20{ }^{\circ} \mathrm{C} \mathrm{min}{ }^{-1}$, under the dynamic atmosphere of nitrogen $\left(50 \mathrm{~mL} \mathrm{~min}^{-1}\right)$. Samples that had the highest Charpy impact resistance were analyzed by this technique.

\subsection{Charpy impact test}

Impact strength tests were performed according to ASTM D6110:17, using a Resil 25R instrumented impact machine from Ceast using a $1.0 \mathrm{~J}$ impactor in injected test specimens at $23{ }^{\circ} \mathrm{C}$, with a pendulum velocity of $2.90 \mathrm{~m} / \mathrm{s}$.

\subsection{Scanning electron microscopy (SEM)}

A low vacuum Scanning electron microscopy, model FEI Quanta 400, was used to evaluate the non-metallized fracture surface of the samples.

\section{Results and Discussion}

\subsection{Charpy impact resistance}

Table 2 and Figure 1 show the results of Charpy impact strength obtained for blends compatibilized with Ionomer.

According to the results (Table 2), it is possible to notice that the impact resistance tends to increase as the percentage of PCTG decreases, and the impact properties tend to be lower when either ABS or PCTG are around $50 \%$.

Regression and analysis of variance (ANOVA) were performed to determine an equation that could predict final impact resistance of the blend in different proportions, within the percentage range of each component previously stipulated.

\subsection{Analysis of mixture design results}

Table 3 presents the statistical data collected regarding the regression performed on the mixtures considering the variable Y1 response (impact resistance).

By adjusting the regression, with $95 \%$ of confidence, the special quadratic model was postulated in Equation 1 for Charpy impact resistance (Y1).

The p-value can be used to assess whether or not the term is significant for the model. If the p-value is less than 0.05 , at a confidence level of $95 \%$, the model term is considered significant.

The $\mathrm{R}^{2}$ value indicates the percentage of response variation around the mean that is explained by the regression, while the adjusted $\mathrm{R}^{2}$ value, despite being similar to the $\mathrm{R}^{2}$ value, does not increase with the inclusion of independent variables that are not significant.

The experimental data were adjusted using the special quadratic model, represented by the Equation 1.

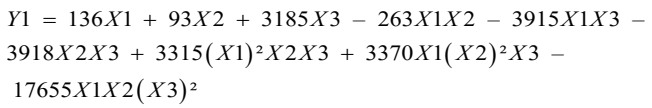

Table 1. Blend compositions.

\begin{tabular}{|c|c|c|c|c|c|}
\hline \multicolumn{3}{|c|}{ Pseudocomponent } & \multicolumn{3}{|c|}{ Components $(\% \mathrm{~m} / \mathrm{m})$} \\
\hline $\mathrm{X} 1$ & $\mathbf{X} 2$ & X3 & ABS & PCTG & IONOMER \\
\hline 1 & 0 & 0 & 79 & 20 & 1 \\
\hline 0.88 & 0 & 0.12 & 73 & 20 & 7 \\
\hline 0.18 & 0.82 & 0 & 39 & 60 & 1 \\
\hline 0.06 & 0.82 & 0.12 & 33 & 60 & 7 \\
\hline 0.94 & 0 & 0.06 & 76 & 20 & 4 \\
\hline 0.59 & 0.41 & 0 & 59 & 40 & 1 \\
\hline 0.12 & 0.82 & 0.06 & 36 & 60 & 4 \\
\hline 0.47 & 0.41 & 0.12 & 53 & 40 & 7 \\
\hline 0.77 & 0.20 & 0.03 & 68 & 30 & 3 \\
\hline 0.70 & 0.20 & 0.09 & 65 & 30 & 6 \\
\hline 0.36 & 0.61 & 0.03 & 48 & 50 & 3 \\
\hline 0.30 & 0.61 & 0.09 & 45 & 50 & 6 \\
\hline 0.53 & 0.41 & 0.06 & 56 & 40 & 4 \\
\hline 0.53 & 0.41 & 0.06 & 56 & 40 & 4 \\
\hline 0.53 & 0.41 & 0.06 & 56 & 40 & 4 \\
\hline
\end{tabular}


where, $\mathrm{X} 1, \mathrm{X} 2$ and $\mathrm{X} 3$ are, respectively, the percentages by weight of ABS, PCTG and Ionomer and, YI represents the value of impact resistance.

The higher the value of $\mathrm{R}^{2}$ and adjusted $\mathrm{R}^{2}$, the better the model fits the data and, therefore the proposed model for impact resistance explains $97.41 \%$ of the data and these values are reliable at a level of $93.95 \%$, respectively.

According to the model adopted for impact resistance, there is a different effect for each variable and interaction, as shown in Table 4.

According to the results presented in Table 4, the addition of ABS, PCTG and Ionomer, in isolation, contribute positively to the equations obtained for impact resistance.

Regarding the interactions between the components, only the interactions $(\mathrm{ABS})^{2 *} \mathrm{PCTG}^{*}$ Ionomer and ABS*(PCTG $)^{2 *}$ Ionomer have positive effects. However, only the interactions ABS*PCTG, ABS*Ionomer, and PCTG*Ionomer have statistical significance.

Figures 2 shows the influence on the impact strength of the percentage variation of the blend components: ABS, PCTG and Ionomer and Figure 3 shows (a) response surface and (b) contour plots, presenting the effects on the impact resistance of the ABS/PCTG/Ionomer blends. The component effect plot represents the influence of each element at the central point of the experimental region on the response values.

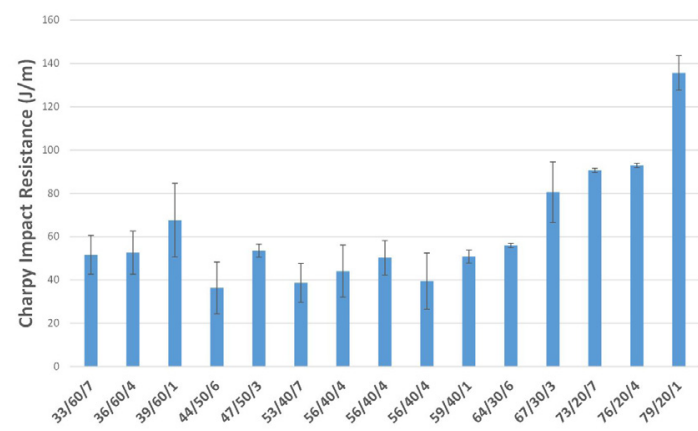

Figure 1. Impact resistance results of ABS/PCTG/Ionomer blends in different proportions.

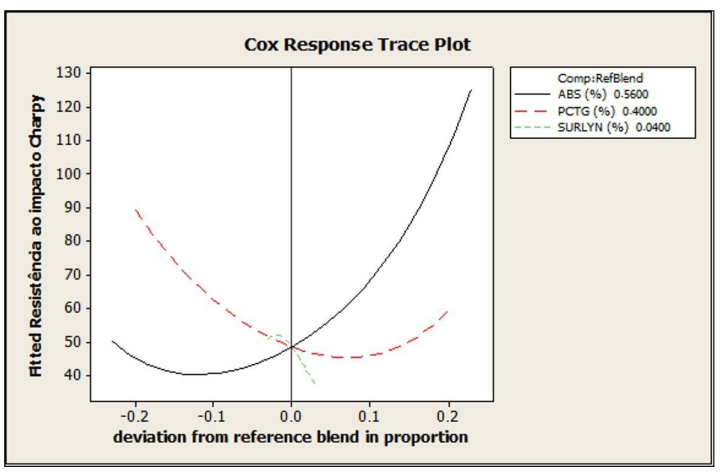

Figure 2. Influence on the impact strength of the percentage variation of the blend components: ABS, PCTG and Ionomer.
According to Figures 2 and 3, in the weighted percentage range of $30 \% \leq \mathrm{ABS} \leq 80 \%, 20 \% \leq \mathrm{PCTG} \leq 60 \%$, and $1 \% \leq$ Ionomer $\leq 7 \%$, it is observed that an increase in PCTG in the mixture is harmful to the impact resistance, as well as Ionomer increasing. However, for extrapolated values of Ionomer, the effect can be the opposite.

Table 2. Average impact resistance values for the ABS/PCTG/ Ionomer blends.

\begin{tabular}{cccc}
\hline ABS (\%) & PCTG (\%) & $\begin{array}{c}\text { IONOMER } \\
\text { (\%) }\end{array}$ & $\begin{array}{c}\text { Charpy } \\
\text { Impact (J/m) }\end{array}$ \\
\hline $\mathbf{7 9}$ & 20 & 1 & $136 \pm 8$ \\
$\mathbf{7 3}$ & 20 & 7 & $91 \pm 1$ \\
$\mathbf{3 9}$ & 60 & 1 & $67 \pm 17$ \\
$\mathbf{3 3}$ & 60 & 7 & $51 \pm 9$ \\
$\mathbf{7 6}$ & 20 & 4 & $93 \pm 1$ \\
$\mathbf{5 9}$ & 40 & 1 & $51 \pm 3$ \\
$\mathbf{3 6}$ & 60 & 4 & $52 \pm 10$ \\
$\mathbf{5 3}$ & 40 & 7 & $38 \pm 9$ \\
$\mathbf{6 7}$ & 30 & 3 & $80 \pm 14$ \\
$\mathbf{6 4}$ & 30 & 6 & $56 \pm 1$ \\
$\mathbf{4 7}$ & 50 & 3 & $53 \pm 3$ \\
$\mathbf{4 4}$ & 50 & 6 & $36 \pm 12$ \\
$\mathbf{5 6}$ & 40 & 4 & $44 \pm 12$ \\
$\mathbf{5 6}$ & 40 & 4 & $50 \pm 8$ \\
$\mathbf{5 6}$ & 40 & 4 & $39 \pm 13$ \\
\hline
\end{tabular}

Table 3. Regression performed for the response variable Y1 (impact resistance) in the $\mathrm{ABS} / \mathrm{PCTG} /$ Ionomer blend.

\begin{tabular}{lccc}
\hline \multicolumn{1}{c}{ Term (\%) } & Coef & SE Coef & p-value \\
\hline ABS & 136.0 & 6.46 & - \\
PCTG & 93.0 & 10.11 & - \\
IONOMER & $3,185.0$ & $1,348.10$ & - \\
ABS*PCTG & -263.0 & 41.73 & 0.001 \\
ABS*IONOMER & $-3,915.0$ & $1,548.01$ & 0.045 \\
PCTG*IONOMER & $-3,918.0$ & $1,567.44$ & 0.047 \\
(ABS) $^{2 *}$ PCTG*IONOMER & $3,315.0$ & $1,465.30$ & 0.064 \\
ABS*(PCTG) ${ }^{2 *}$ IONOMER & $3,370.0$ & $1,582.85$ & 0.077 \\
ABS*PCTG*(IONOMER) $^{2}$ & $-17,655.0$ & $8,636.61$ & 0.087 \\
R $^{2}$ & $97.41 \%$ & & \\
Adjusted R & $93.95 \%$ & & \\
\hline
\end{tabular}

Coef: Coefficient; SE Coef: Standard error of the coefficient; $\mathrm{R}^{2}$ : Coefficient of determination; Adjusted $\mathrm{R}^{2}$ : Adjusted coefficient of determination.

Table 4. Effects of variables with Ionomer compatibilizer.

\begin{tabular}{lcc}
\hline \multicolumn{1}{c}{ Interaction } & Effect & $\begin{array}{c}\text { Statistical } \\
\text { significance } \\
\text { (p-value }<\mathbf{0 . 0 5})\end{array}$ \\
\hline ABS & Positive & - \\
PCTG & Positive & - \\
Ionomer & Positive & - \\
ABS*PCTG & Negative & Significant \\
ABS*Ionomer & Negative & Significant \\
PCTG *Ionomer & Negative & Significant \\
$(\mathrm{ABS})^{2}$ PCTG* $^{*}$ Ionomer & Positive & Not Significant \\
${\text { ABS* }\left(\text { PCTG }^{2 *} \text { Ionomer }\right.}$ & Positive & Not Significant \\
ABS*PCTG*(Ionomer $^{2}$ & Negative & Not Significant \\
\hline
\end{tabular}




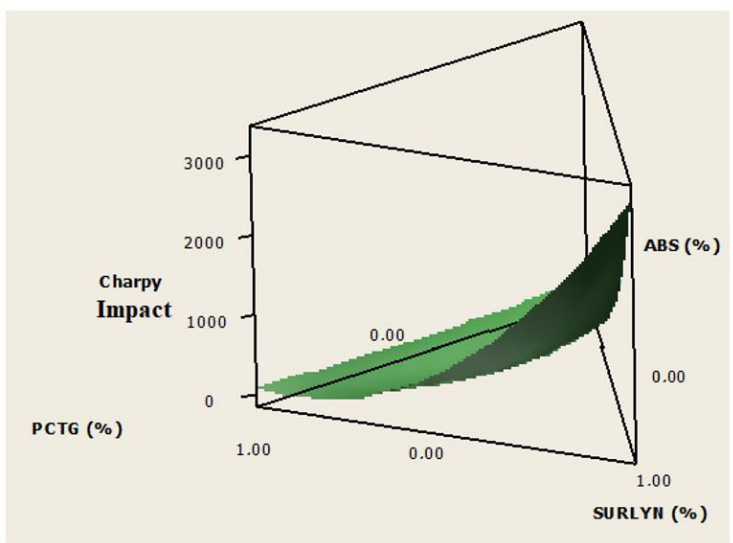

(a)

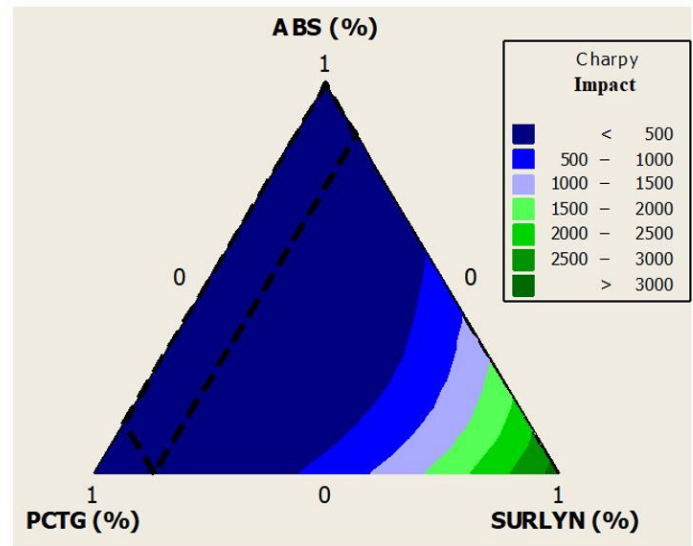

(b)

Figure 3. (a) Response surface and (b) contour plots showing the effects on the impact resistance of the ABS/PCTG/Ionomer blends.

Table 5. ANOVA for impact resistance (Y1), ABS/PCTG/Ionomer blend.

\begin{tabular}{|c|c|c|c|c|c|c|}
\hline ANOVA & DF & Seq SS & Adj SS & Adj MS & $\mathbf{F}$ & p-value \\
\hline Regression & 8 & $9,896.0$ & $9,896.05$ & $1,237.01$ & 28.19 & 0 \\
\hline Linear & 2 & $5,520.2$ & 983.48 & 491.74 & 11.21 & 0.009 \\
\hline Quadratic & 3 & $4,100.7$ & $1,949.28$ & 649.76 & 14.81 & 0.004 \\
\hline ABS*PCTG & 1 & $4,020.3$ & $1,740.36$ & $1,740.36$ & 39.67 & 0.001 \\
\hline ABS*IONOMER & 1 & 23.3 & 280.69 & 280.69 & 6.40 & 0.045 \\
\hline PCTG*IONOMER & 1 & 57.1 & 274.17 & 274.17 & 6.25 & 0.047 \\
\hline Spacial Cubic & 3 & 275.2 & 275.15 & 91.72 & 2.09 & 0.203 \\
\hline$(\mathrm{ABS})^{2 *} \mathrm{PCTG} *$ IONOMER & 1 & 68.9 & 224.52 & 224.52 & 5.12 & 0.064 \\
\hline ABS*(PCTG) $)^{2 *}$ IONOMER & 1 & 22.9 & 198.94 & 198.94 & 4.53 & 0.077 \\
\hline ABS*PCTG*(IONOMER $)^{2}$ & 1 & 183.3 & 183.34 & 183.34 & 4.18 & 0.087 \\
\hline Residual error & 6 & 263.3 & 263.25 & 43.88 & - & - \\
\hline Lack of adjustment & 4 & 205.3 & 205.26 & 51.32 & 1.77 & 0.392 \\
\hline Pure error & 2 & 58.0 & 57.99 & 28.99 & - & - \\
\hline Total & 14 & $10,159.3$ & - & - & - & - \\
\hline
\end{tabular}

DF: degree of freedom; Seq SS: sum of the sequential squares; Adj SS: adjusted sum of squares; Adj MS: mean of squares; F: F-test.

Table 5 presents the analysis of variance (ANOVA) for impact resistance.

Each SS (Sequential or adjusted) is associated with a number of degrees of freedom (D.F), which indicates the number of independent values involving the " $n$ " observations that are necessary to determine it.

According to the results presented, the Adj SS value of the regression is higher than the Adj SS value of the residuals. It indicates that the fraction described by the regression is more representative than the fraction described by the residuals, since the Adj SS of the residuals provides information about the part of the response variation that the model cannot reproduce.

The quadratic sum of the residuals can be decomposed into quadratic sum due to the pure error and also due to the lack of adjustment.
Thus, for the model proposed for impact resistance, the value of Adj SS pure error is lower than for the lack of adjustment, which demonstrates that the pure error associated with the results is small and the model has a variation in the adjustment.

The adjusted quadratic mean of the residuals (Adj MS residuals) can be interpreted as an "average error" (quadratic) that is made when using the regression equation to predict a response.

From the data presented in Table 5, it is possible to verify how much the proposed model fits with the collected data. For this, it is necessary to satisfy requirements 1-3 (Table 6), since Ftab is the tabulated value of Fisher-Snedecor that is 4.15 for $\mathrm{F}(8 ; 6) 19.25$ for $\mathrm{F}(4 ; 2)$ in this case:

It was found that the proposed model for impact resistance fits very well with the data collected, since all the requirements have been met and the residues are randomly dispersed. 
Table 6. Requirements for adjusting the proposed model to the data.

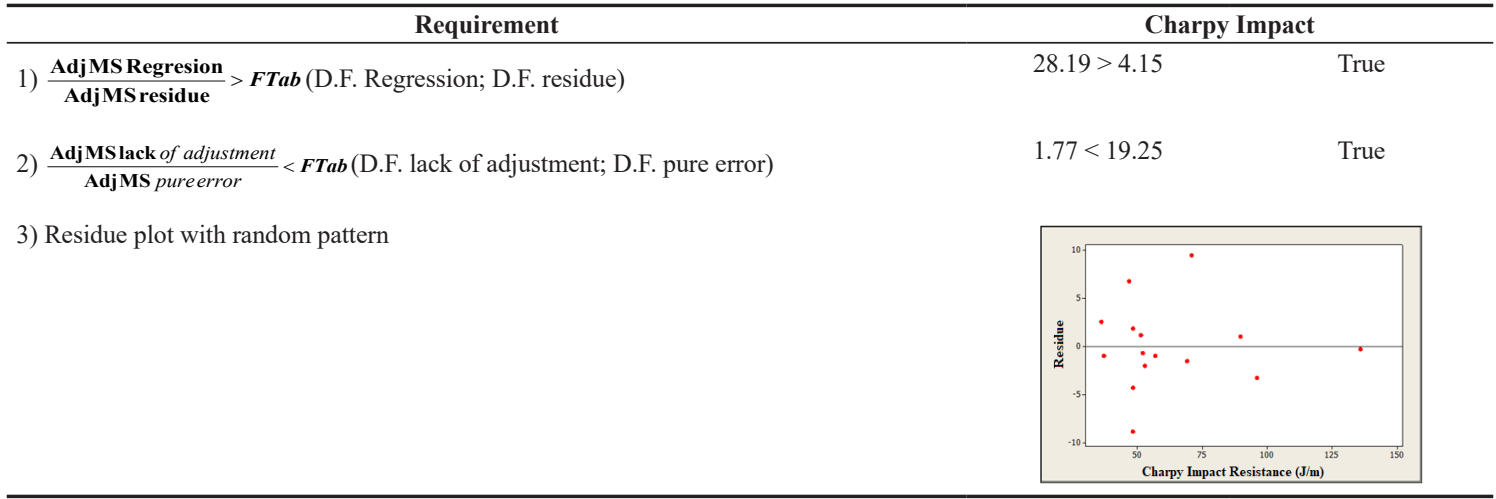

DF: degree of freedom

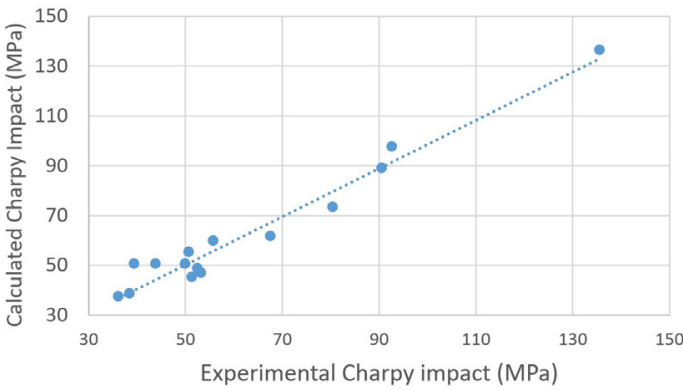

Figure 4. Experimental value vs. calculated value, using the proposed model for impact resistance with Ionomer compatibilizer.

Figure 4 summarizes the experimental values of the impact resistance and the calculated values using the model proposed in Equation 1.

It can be concluded that, through the proposed model, it was possible to predict the final properties of the blend, since the theoretical values were very close to the experimental results.

\subsection{Compatibility analysis}

$\mathrm{ABS} / \mathrm{PCTG} /$ Ionomer 79/20/1 blend which presented the highest impact resistance result was selected to be analyzed by DSC and Scanning Electron Microscopy (SEM) in order to evaluate the compatibility between the components.

Neat components, ABS and PCTG, as well as the blend 79/20/1 were analyzed by DSC in order to determine the glass transition temperature. The results are shown in Figure 5.

One of the criteria to evaluate the miscibility in polymer blends is the analysis of the glass transition temperature ${ }^{[12-}$ ${ }^{14]}$. A blend can be considered miscible when there is only one glass transition temperature, depending on the blend composition. On the other hand, for a partially miscible blend, two or more glass transitions can be observed and attributed to the phases of the blend. It can be emphasized the glass transitions of the phases are shifted relative to that of the neat components. In this case, each phase consists of a miscible mixture containing different compositions ${ }^{[12-14]}$.

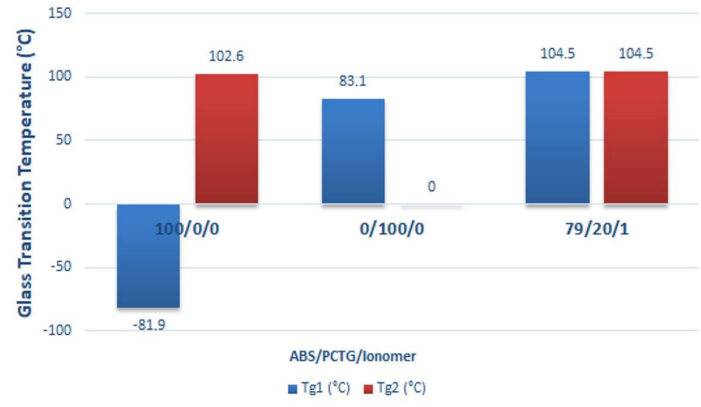

Figure 5. DSC results for the analyzed samples.

Finally, for immiscible polymer blends, there is no intermediate glass transition temperature. In this case, the glass transition temperatures of the phases are close to those of the neat components ${ }^{[12-15]}$.

According to the results shown in Figure 5, it is clear that the Tg of 79/20/1 ABS/PCTG/Ionomer blend, attributed to the PCTG-rich phase, was shifted to higher temperatures. The same behavior was observed for the ABS-rich phase. However, the displacement was more subtle, indicating that the $\mathrm{ABS} / \mathrm{PCTG} /$ Ionomer blend is partially miscible.

The fracture surface of the Charpy impact resistance specimen was analyzed to explore the compatibility mechanism.

An incompatible blend consists of a continuous phase and a dispersed phase which presents larger particles the greater the immiscibility between the components of the blend. This phenomenon occurs due to the coalescence of dispersed phase when there is a high interfacial tension between the components ${ }^{[13,14]}$.

On the other hand, when two immiscible polymers are mixed using compatibilizing agent, the interfacial tension between the dispersed and continuous phase is decreased and the coalescence phenomenon decreases. Compatibilizer can change the morphology of blend as smaller sites of the dispersed phase can be observed randomly distributed throughout the matrix that will improve final mechanical properties ${ }^{[13,14]}$.

Figure 6 shows the micrographs of 79/21/1 ABS/PCTG/ Ionomer blend. It can be seen that PCTG-rich phase is dispersed 
as fibers, indicated by the arrows in the images. This may have occurred due to the presence of the compatibilizing agent that reduced the interfacial energy and prevented the particles from coalescing. As a result of the compatibilizing effect, the adhesion in the interface region became more effective, as it can be observed that most fibers are broken and not detached. This analysis corroborates the high impact resistance result discussed above.

Although PCTG and PETG are different polymers, they have a chemical similarity. Zhang et al. ${ }^{[16]}$ studied the compatibility between PP/PETG blends using different compatibilizing agents. In his work, the tendency for PETG to be dispersed in the form of fibers in the matrix was identified and the result of impact resistance was associated with this behavior. Similar morphology was observed in some other works ${ }^{[16-18]}$.

This may have occurred due to the presence of the compatibilizing agent which reduced the interfacial energy and prevented the particles from coalescing. As a result of the compatibilizing effect, the adhesion in the interface region became more effective, as it can be observed that most fibers are broken and not detached. This analysis corroborates the high impact resistance result discussed above.

Regarding the mechanism of action of the ionomer as compatibilizer in the ABS/PCTG blend, it is suggested that it behaved as an emulsifier agent in the mixture and the compatibilization may have occurred through an acidolysis reaction, where $\mathrm{R}$ is the aliphatic carboxylic acid from the ionomer (Figure 7). Samios and Kalfoglou ${ }^{[19]}$ and Dekoninck et al. ${ }^{[20]}$ also observed this same mechanism, for blends between ABS/ PETG and ABS/PET, respectively (Equation 2).

$$
2 P C T G+R-C O O N a \rightarrow P C T G-C O O N a+P C T G-R
$$

Regarding the interaction between ABS and the Ionomer, it is suggested that the group -COONa of the ionomer tends to remove electrons from the styrenic group of $\mathrm{ABS}$, which tends to release electrons ${ }^{[19,20]}$, as shown in Figure 8. This

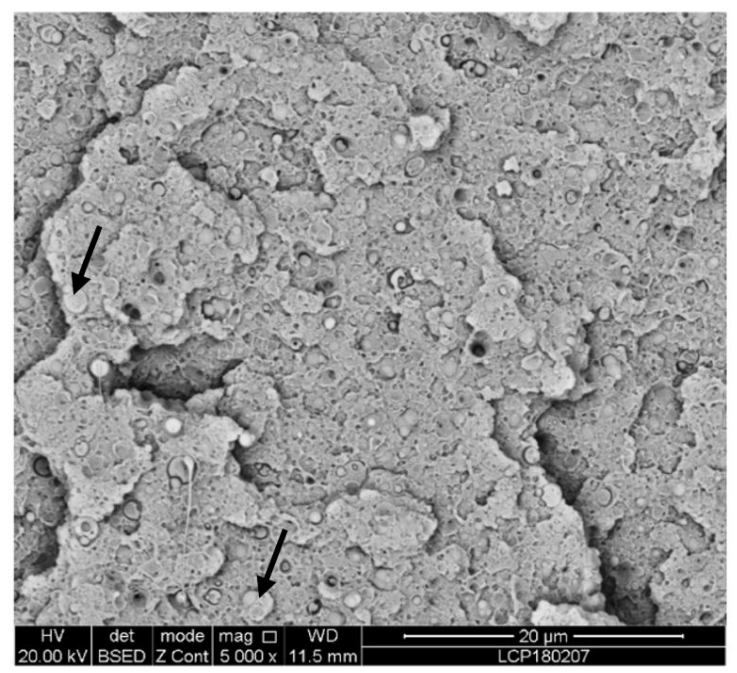

(a)

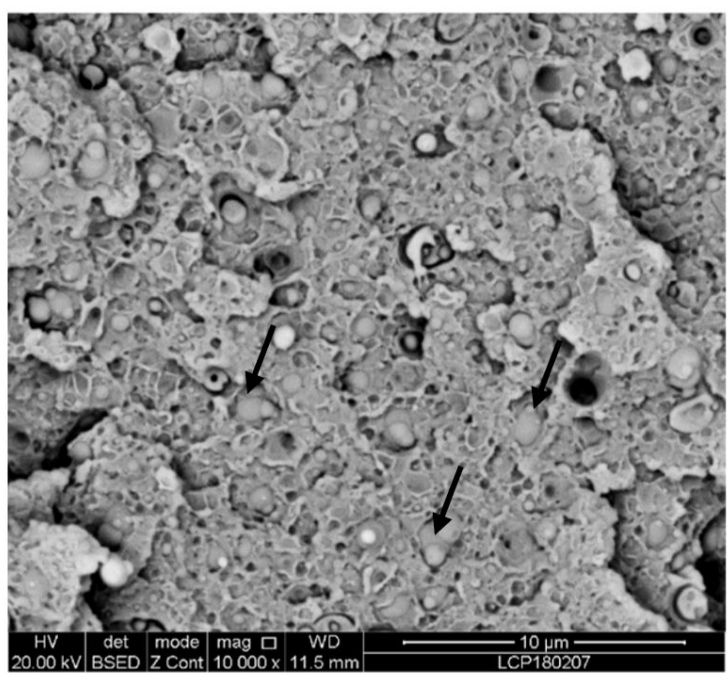

(b)

Figure 6. Micrograph of the fracture surface of the ABS/PCTG/Ionomer sample (79/20/1) with magnification of (a) $5000 \mathrm{x}$ (b) $10000 \mathrm{x}$.

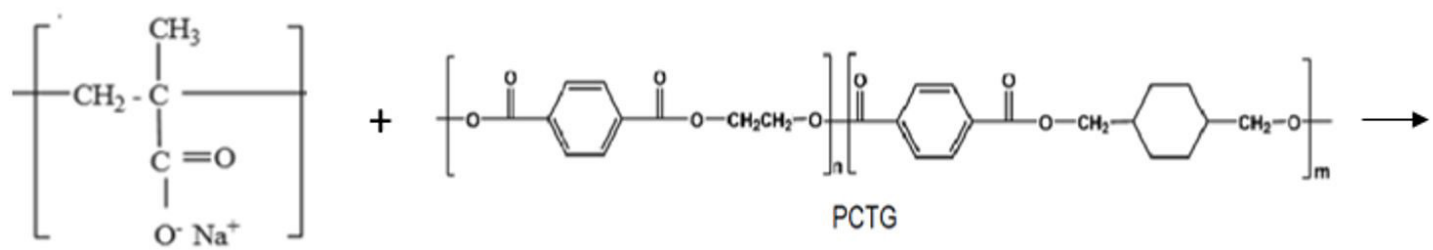

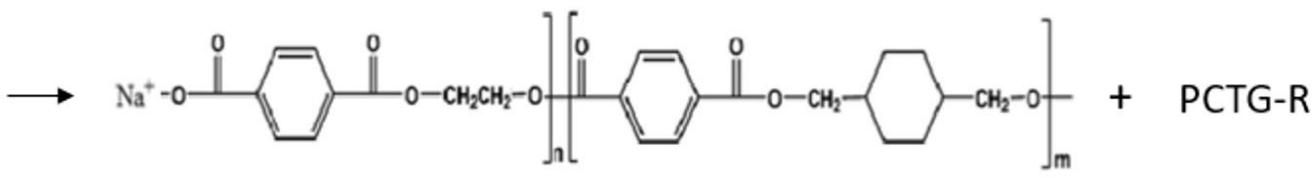

Figure 7. Possible compatibility reaction by acidolysis between PCTG/Ionomer in the blend between ABS/PCTG/Ionomer. 

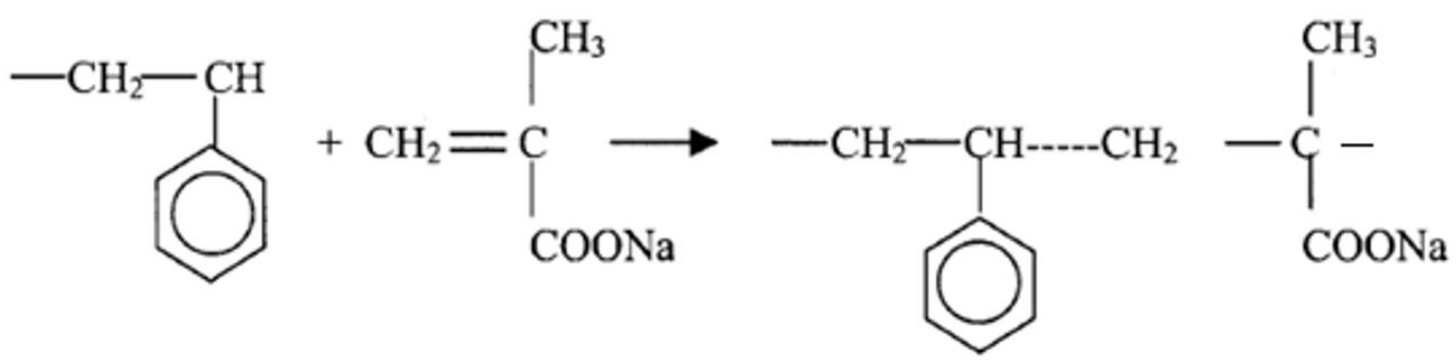

Figure 8. Possible reaction of compatibility between ABS/Ionomer in the blend between ABS/PCTG/Ionomer.

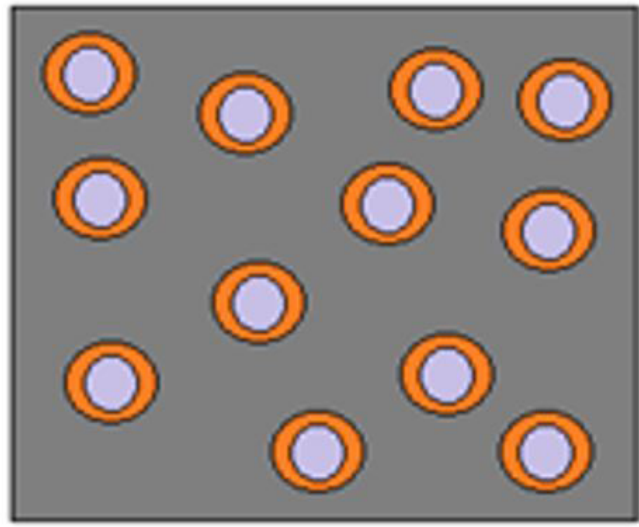

\section{PCTG}

with Ionomer

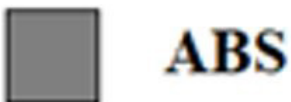

Figure 9. Scheme of the morphology and mechanism of action of the compatibilizer for 79/20/1 blend (ABS/PCTG/Ionomer).

theory was also observed by Ismail and $\mathrm{Nasir}^{[21]}$ for blends between polystyrene and polypropylene, using ionomer as a compatibilizer.

Figure 9 summarizes the compatibilization action of the Ionomer in the ABS/PCTG blend morphology.

It can be concluded that the ionomer acted as a good compatibilizing agent both in the ABS-rich phase and in the PCTG-rich phase, since PCTG was presented as small-sized fibers homogeneously dispersed in the matrix. Therefore, it was possible to ensure partial miscibility of the ABS/PCTG/Ionomer blend improving its performance on impact resistance tests.

\section{Conclusion}

According to the results, it is possible to conclude that the impact resistance decreases with the PCTG content increasing in the mixture, as well as the increase of the ionomer proportion. The blend composition that presented the best performance regarding the impact resistance was 79/21/1 (ABS/PCTG/Ionomer).

It was possible to establish a viable equation to predict Charpy impact resistance for the blend between the components within the concentration range used in this study through the modeling of the experiments. The equation can be useful in determining the most suitable proportions to mix the components in order to predict the final impact resistance of the blend and ensure the feasibility to reuse/ recycle industrial PCTG waste.

The morphological analysis of the fracture surface and DSC analysis showed that the blend 79/20/1 had a partial miscibility. The PCTG as a dispersed phase presented the form of fibers with reduced sizes and homogeneous dispersion. It is suggested that the ionomer acted as an emulsifier, interacting with both components of the blend.

\section{Acknowledgements}

Authors thank to ITA for the support provided for the preparation of the study.

\section{References}

1. Hamaide, T., Deterre, R., \& Feller, J.-F. (Eds.). (2014). Environmental impact of polymers. Hoboken: ISTE. http:// dx.doi.org/10.1002/9781118827116.

2. Ivleva, N. P., Wiesheu,A. C., \& Niessner, R. (2017). Microplastic in aquatic ecosystems. Angewandte Chemie International Edition, 56(7), 1720-1739. http://dx.doi.org/10.1002/anie.201606957. PMid:27618688.

3. Maris, J., Bourdon, S., Brossard, J.-M., Cauret, L., Fontaine, L., \& Montembault, V. (2018). Mechanical recycling: compatibilization of mixed thermoplastic wastes. Polymer Degradation \& Stability, 147, 245-266. http://dx.doi.org/10.1016/j. polymdegradstab.2017.11.001.

4. Vilaplana, F., \& Karlsson, S. (2008). Quality concepts for the improved use of recycled polymeric materials: a review. Macromolecular Materials and Engineering, 293(4), 274-297. http://dx.doi.org/10.1002/mame.200700393.

5. La Mantia, F. P. (1998). Reprocessing and properties of homopolymer blends of virgin and recycled polymers. In G. Akovali, C. A. Bernardo, J. Leidner, L. A. Utracki \& M. Xanthos (Eds.), Frontiers in the science and technology of polymer recycling (pp. 371-385). Dordrecht: Springer. http:// dx.doi.org/10.1007/978-94-017-1626-0_17. 
6. Joseph, S., Focke, W. W., \& Thomas, S. (2010). Compatibilizing action of a poly(styrene-butadiene) Triblock co-polymer in ABS/PET-G blends. Composite Interfaces, 17(2-3), 175-196. http://dx.doi.org/10.1163/092764410X490590.

7. Heo, Y. M., Koo, J. M., Hwang, D. K., JaeGal, J. G., Hwang, S. Y., \& Im, S. S. (2016). Synthesis and characteristics of biobased copolyester for thermal shrinkage film. RSC Advances, 6(62), 57626-57633. http://dx.doi.org/10.1039/C6RA10333B.

8. Chen, T., Jiang, G., \& Zhang, J. (2014). Isothermal crystallization behavior and crystal structure of poly(ethylene terephthalateco-1,4-cyclohexylene dimethylene terephthalate) $(\mathrm{P}(\mathrm{ET} / \mathrm{CT}))$ copolyesters. Crystal Research and Technology, 49(4), 232-243. http://dx.doi.org/10.1002/crat.201300369.

9. Cook, W. D., Moad, G., Fox, B., Deipen, G. V., Zhang, T., Cser, F., \& McCarthy, L. (1996). Morphology-property relationships in ABS/PET blends. II. Influence of Processing conditions on structure and properties. Journal of Applied Polymer Science, 62(10), 1709-1714. http://dx.doi.org/10.1002/(SICI) 1097 4628(19961205)62:10<1709::AID-APP22>3.0.CO;2-V.

10. Chen, T., \& Zhang, J. (2018). Compatibilization of acrylonitrile-butadiene-styrene terpolymer/poly(ethylene glycol-co-1,4-cyclohexanedimethanol terephthalate) blend: effect on morphology, interface, mechanical properties and hydrophilicity. Applied Surface Science, 437, 62-69. http:// dx.doi.org/10.1016/j.apsusc.2017.12.168.

11. Koning, C., Duin, M., Pagnoulle, C., \& Jerome, R. (1998). Strategies for compatibilization of polymer blends. Progress in Polymer Science, 23(4), 707-757. http://dx.doi.org/10.1016/ S0079-6700(97)00054-3.

12. Olabisi, O., Robeson, L. M., \& Shaw, M. T. (1979). Polymerpolymer miscibility. New York: Academic Press. http://dx.doi. org/10.1016/B978-0-12-525050-4.X5001-X.

13. Utracki, L. A. (2003). Introduction to polymer blends. Dordrecht: Springer. http://dx.doi.org/10.1007/0-306-48244-4_1.

14. Paul, D. P., \& Bucknall, C. B. (1999). Polymer blends: formulation and performance. New York: John Wiley \& Sons.
15. Thirtha, V. M., Lehman, R. L., \& Nosker, T. J. (2004). Morphological effects on glass transitions in immiscible polymer blends. MRS Online Proceedings Library, 856, 1112. http://dx.doi.org/10.1557/PROC-856-BB11.12.

16. Zhang, X., Li, B., Wang, K., Zhang, Q., \& Fu, Q. (2009). The effect of interfacial adhesion on the impact strength of immiscible PP/PETG blends compatibilized with triblock copolymers. Polymer, 50(19), 4737-4744. http://dx.doi. org/10.1016/j.polymer.2009.08.004.

17. Li, B., Zhang, X., Zhang, Q., Chen, F., \& Fu, Q. (2009). Synergistic enhancement in tensile strength and ductility of ABS by using recycled PETG plastic. Journal of Applied Polymer Science, 113(2), 1207-1215. http://dx.doi.org/10.1002/ app.30002.

18. Chen, T., \& Zhang, J. (2016). Surface hydrophilic modification of acrylonitrile-butadiene-styreneterpolymer by poly(ethylene glycol-co-1,4-cyclohexanedimethanolterephthalate): preparation, characterization, and properties studies. Applied Surface Science, 388, 133-140. http://dx.doi.org/10.1016/j.apsusc.2016.02.242.

19. Samios, C. K., \& Kalfoglou, N. K. (2001). Acrylic-modified polyolefin ionomers as compatibilizers for poly(ethylene-covinyl alcohol)/aromatic copolyester blends. Polymer, 42(8), 3687-3696. http://dx.doi.org/10.1016/S0032-3861(00)00432-8.

20. Dekoninck, J. M., Legras, R., \& Mercier, J. P. (1989). Nucleation of poly(ethylene terephthalate) by sodium compounds: a unique mechanism. Polymer, 30(5), 910-913. http://dx.doi. org/10.1016/0032-3861(89)90191-2.

21. Ismail, H., \& Nasir, M. (2002). The effect of various Compatibilizers on mechanical properties of polystyrene/ polypropylene blend. Polymer Testing, 21(2), 163-170. http:// dx.doi.org/10.1016/S0142-9418(01)00064-2.

Received: Sept. 16, 2021

Revised: Oct. 18, 2021

Accepted: Oct. 24, 2021 